\title{
NORUS
}

ISSN: $2318-1966$

v. 3, n. 4

jul - dez 2015

Dossiê

\section{AMBIENTALISMO E SUSTENTABILIDADE: UM OLHAR SOBRE O DISCURSO AMBIENTAL}

\author{
Rachel Souza Martins \\ Doutora em Filosofia pela UFRJ
}

\begin{abstract}
RESUMO
O presente artigo introduz uma análise da questão ambiental e de seus desdobramentos na arena social, inserindo o debate sobre o meio ambiente no cerne da sociedade humana. O presente estudo abordará a ideia da construção de uma 'socionatureza' como o ponto de partida para as discussões acerca do meio ambiente. Neste sentido, a questão ambiental será analisada a partir de um viés filosófico e antropológico. Caberá a esta análise, apontar críticas ao modo como o discurso ambiental se constituiu ao longo da história da humanidade, alicerçando os valores que atribuímos à natureza. $\mathrm{O}$ artigo apresenta, num segundo momento, o surgimento dos movimentos ambientalistas e a importância destes para a construção de uma visão social acerca da natureza, introduzindo também os debates sobre os temas da justiça social e ambiental como questões fundamentais para a ampliação do discurso ético e ambiental. A proposta deste estudo será, assim, apresentar uma visão ética capaz de englobar a questão ambiental a ser exposta, bem como orientar o debate ambiental para um discurso calcado em noções firmes de sustentabilidade e justiça.
\end{abstract}

Palavras-chave: Ambientalismo, justiça ambiental, desenvolvimento sustentável, ética ambiental.

\section{ENVIRONMENTALISM AND SUSTAINABILITY: AN APPROACH OF THE ENVIRONMENTAL DEBATE}

\begin{abstract}
This article aims to analyze the environmental issues and its outspread ideas in the social arena, including the environmental debate in the core of human society. The present work will approach the idea of 'socionature' as a starting point for the debate about the environment. In this way, environmental issues will be analyzed from a philosophical and an anthropological perspective. The role of this analysis will be to criticize the way as environmental debate has been constituted in
\end{abstract}


NORUS - v3, n.4, jul - dez 2015.

human history over time, basing the values assigned to nature. The article presents, in the following debate, the appearance of the environmental movements and its relevance for a social view of nature, showing the social and the environmental justice debates as fundamental ideas for enlarging an ethical and environmental view. The proposal of this study will be to present an ethical view that encloses the environmental perspective as well as to guide the environmental debate into a firm notion of sustainability and justice.

Keywords: Environmentalism, environmental justice, sustainable development, environmental ethics.

\section{INTRODUÇÃO}

A questão ambiental que insurge no momento atual apresenta diversas facetas e temáticas debatidas em âmbito global. Neste momento, teóricos, cientistas e políticos voltam-se para o meio ambiente e tecem questões com caráter de urgência a serem debatidas, produzindo meios para combater alguns danos já visíveis. A denúncia dos graves problemas ambientais produzidos pelo ser humano neste período de nossa história aparece como algo alarmante para a humanidade, exigindo mudanças radicais em nosso modo de vida e apontando para a mudança de paradigmas do ser humano frente aos debates empreendidos sobre e o meio ambiente e a cultura.

O presente estudo tem por objetivo colocar questões relativas tanto ao modo como o discurso ambiental vem sendo construído em nossa sociedade, como também à visão ética aplicada aos debates sobre a natureza. Faz-se necessário, numa perspectiva filosófica, adotar uma posição crítica frente aos discursos paradigmáticos que apresentam uma segmentação entre o meio ambiente e a produção humana, entre homem e natureza, apontando para a integração histórica entre estes conceitos. A perspectiva tradicional que compreende a natureza como algo completamente externo ao ser humano, definido tanto como sagrado ou puro, numa visão romântica da natureza, quanto como objeto de uso, numa visão mecanicista da mesma, será aqui combatida em prol de um discurso que realmente contribua para uma melhor compreensão da ideia de meio ambiente. Segundo esta visão, conceber a natureza ou meio ambiente como algo isento de intervenções, seria como analisar o mundo de forma 'acrítica' (DEMERITT, 2001).

As segmentações apresentadas no discurso acerca do meio ambiente permitem que se trate a noção de desenvolvimento econômico como algo desvinculado da ideia de meio ambiente, considerando a questão ambiental como secundária e excluindo a influência e impacto diretos que a economia, vinculada à tecnologia, impõe à natureza, compreendida agora de modo inter-relacional.

A perspectiva a ser abordada neste estudo partirá, portanto, de uma visão construtivista da natureza, denominada 'socionatureza', considerada aqui uma perspectiva crítica sobre os debates 


\section{Ambientalismo e sustentabilidade: um olhar sobre o discurso ambiental}

ambientais. Partindo da perspectiva de Noel Castree (2001) que concebe a natureza a partir de seu caráter intrinsecamente social, pretende-se abordar a questão ambiental como parte integral das relações humanas de produção e seus impactos para com o ambiente. Tendo em vista esta concepção, o debate sobre os temas presentes na atualidade deve considerar a natureza como espaço de transformações sociodinâmicas que alteram tanto a paisagem de áreas florestais distantes, quanto os ambientes urbanos, que devem ser inseridos no âmbito dos discursos ambientais na atualidade, haja vista toda a problemática da população, do consumo e a demanda de recursos nos grandes centros.

A teoria construtivista da natureza aparece no cenário histórico na década de 1970 entre os principais eixos temáticos da geografia política e aborda questões como a justiça ambiental e o problema da escassez de recursos, bem como de sua distribuição, que ainda não faziam parte da agenda dos movimentos ambientalistas. A introdução da perspectiva social no contexto ambiental representa uma mudança profunda nos paradigmas socioculturais no que tange ao modo como eram tratadas as questões ambientais. Até este momento, uma visão conservacionista se impunha no contexto ambiental paralelamente à ética da terra, que constituiu as bases da ecologia profunda. A ecologia profunda será marcante neste sentido por instituir uma visão radical acerca da relação do homem com a natureza, exigindo o mínimo de impacto e a supressão do desenvolvimento econômico global assim como a redução do crescimento populacional.

A proposta deste estudo será, portanto, a de superar inicialmente a dicotomia 'homemnatureza' bastante arraigada na cultura antropocêntrica e promover, assim, o conhecimento e a ética a partir de uma perspectiva da natureza atrelada às questões sociais. A questão muda de foco com a teoria construtivista da natureza na medida em que o homem aparece como um dentre os diversos atores que exercem ações em seu meio. Deste modo, não é apenas o homem que transforma a natureza, ou sequer a natureza deverá ser compreendida como objeto externo ao ser humano, mas como parte dos elementos que compõem a teia da 'socionatureza'. Partindo de uma visão ampla de natureza como uma construção social, é possível compreender que as características apresentadas pela natureza não podem ser consideradas fixas ou universais, mas são transformações socioambientais. Estas transformações envolvem aspectos diversos que se conectam de diferentes formas, também gerando conflitos e tensões, como podemos ver na afirmação de Eric Swyngedouw (1999).

Urban areas, regions, or any other outcome of sociospacial process or conditions exist in a network of interwoven processes that are simultaneously human, natural, material, cultural, mechanical and organic. The myriad processes that support and maintain social life, such 
as, for example, water, energy, food or computers always combine society and nature in infinite ways; yet simultaneously, these hybrid socionatural "things" are full of contradictions, tensions and conflicts. (SWYNGEDOUW, 1999, p. 445).

Com base na perspectiva da 'socionatureza' como uma construção social atrelada a diversos fatores de ordens natural, políticas, econômicas, etc., pode-se atentar para problemas oriundos dos assim chamados 'híbridos', uma vez que são combinações complexas que levam a humanidade a questionar seus efeitos no ambiente. Contudo, os elementos híbridos entre sociedade e natureza são partes de um mecanismo global que vem se intensificando com o desenvolvimento das novas tecnologias impulsionadas pela modernidade. Não cabe, contudo, procurar eliminar os objetos híbridos entre sociedade e natureza, mas é parte de uma abordagem crítica repensar o discurso que aponta para a proliferação dos híbridos e para a construção social da natureza, concebida até mesmo como uma 'nova natureza' como um discurso neutro.

Nesta concepção acerca de uma 'nova natureza' inserem-se questões sobre as transformações de sistemas ecológicos em áreas urbanas, a transformação de objetos em recursos naturais e os inúmeros processos sociais sobre os quais o uso e a distribuição destes recursos envolvem. Todo este processo é caracterizado como um processo histórico-geográfico embasado por uma concepção dialética que promove a ideia de integração entre as práticas históricas da humanidade e suas condições materiais (geográficas), produzindo também uma representação simbólica da natureza presente nos discursos apresentados sobre a natureza. O que se pretende discutir aqui, neste aspecto, é que a produção desta nova natureza concebida através de suas transformações socioambientais e da proliferação de híbridos, está intrinsecamente associada às relações de poder que impõem "noções de progresso, emancipação e melhoramentos" (SWYNGEDOUW, 1999, p. 449).

Pretende-se discutir, a partir disto, como as mudanças histórico-geográficas relacionam-se com a questão da justiça ambiental e social, elaborando uma concepção ética frente aos problemas encontrados tanto no âmbito dos discursos ambientalista, científico e político, embasados em noções antropocêntricas, quanto no âmbito das práticas reais do homem para com a sociedade e a natureza, entendidas de modo indissociável. Cabe, portanto, ao momento presente, tratar problemáticas de cunho social também como questões cerceadas pela história da relação humana com o meio ambiente marcada pelo mecanicismo do pensamento moderno que considerava a natureza como uma instância autônoma criada para o domínio humano. Cabe, portanto, inserir o discurso ambiental numa perspectiva global considerando o caráter híbrido das relações a serem discutidas neste estudo. 


\section{Ambientalismo e sustentabilidade: um olhar sobre o discurso ambiental}

\section{Um olhar sobre a história ambiental}

Tendo em vista o cenário global de transformações que configuram a crise ambiental enfrentada nos dias atuais, é possível abordar aqui questões relativas à justiça social e aos valores da humanidade enquanto questões que permeiam o debate ambiental. No momento atual, presenciamos a ênfase nos discursos que valorizam a 'consciência ambiental' e em movimentos ambientalistas que promovem a preservação e o 'desenvolvimento sustentável' como slogans para a resolução da crise ambiental enfrentada. É necessário que se analise e discuta os propósitos e concepções que colocam estas temáticas como pautas centrais da questão ambiental global e que se proponha um olhar crítico às possíveis estratégias de poder que financiam ideologias.

Observando atentamente a história ambiental, notamos que o processo de colonização e expansão da população global para outros continentes fora marcado pelo uso de técnicas e práticas que pretendiam tornar as diversas regiões habitáveis e próprias para o uso, através de agricultura prioritariamente. Tais processos transformadores do ambiente refletem o que chamamos acima de 'híbridos', uma vez que modificaram definitivamente a natureza. Não fora, contudo, a simples intervenção humana no meio ambiente, mas as práticas utilizadas mostraram-se nocivas para a manutenção das mesmas e para a preservação do espaço para as gerações futuras. Trazendo à tona novamente a abordagem construtivista da natureza, nota-se que todas as transformações humanas e a construção de um espaço social e urbano pela humanidade são vistas como intervenções específicas, porém não problemáticas a princípio. Posteriormente é que as práticas da humanidade poderão ser pensadas sob uma ótica crítica que irá requerer suas mudanças.

É notável que, no passado, a humanidade abraçara plenamente o ideal do progresso refletido no domínio da natureza, compreendida duplamente como 'lugar sagrado', dando-lhe o caráter de algo intocável e puro, quanto como matéria-prima potencial pronta para ser manipulada de modo irrestrito. $\mathrm{O}$ conflito presente numa ideia ambígua da natureza não contribui imediatamente para a visão preservacionista, mas apenas institui uma relação do homem com a natureza pautada em valores antropocêntricos que afirmam: i. A natureza é a matéria-prima e fonte de recursos a serem extraídos e manejados pelo homem; ii. O homem é a criatura dotada de razão e, portanto, o único com o poder de controlar a natureza (que não possui razão); iii. O homem necessita de reservas naturais para seu lazer e entretenimento e iv. Alguns recursos devem ser preservados, uma vez que a humanidade não sobreviverá sem eles. Ocorre que a subordinação dos elementos da natureza, bem como dos demais seres vivos aos interesses exclusivos da humanidade os torna meros recursos da humanidade e objetos para o seu uso contínuo. 
NORUS - v3, n.4, jul - dez 2015.

Observa-se, como isto, que, embora a noção de preservação viesse à tona em algum momento da história, o enfoque central da relação humana para com o meio ambiente era marcado pela dicotomia apresentada entre o 'ser racional' ou 'sujeito pensante' como estabelecido na modernidade por Descartes e a natureza, que era desprovida de 'alma', 'pensamento' e também 'valor'. Alcança-se com isto uma visão importante para o debate ambiental ao referirmo-nos aqui à questão do valor atribuído à natureza. Fica claro então que, ao impor o ideal antropocêntrico às relações humanas, o único sujeito a ser considerado moralmente é o ser humano e todo o seu entorno possui apenas valor instrumental enquanto objeto para o uso e desfruto humano. Somente após o lançamento da teoria de Darwin sobre a evolução das espécies e da crise do pensamento moderno no que tange à supremacia do sujeito pensante, é que fora possível retirar o homem de sua visão centralizadora e inseri-lo no mesmo patamar da natureza, podendo agora compreendê-la integralmente como parte de suas práticas e imersa nas relações transformadoras da sociedade.

A questão do valor atribuído ao meio ambiente ainda gera grandes discussões filosóficas, visto que o ideal preservacionista que aflora após a longa trajetória da humanidade em sua relação de exclusão da natureza, ainda é imerso em valores antropocêntricos que instrumentalizam o valor do meio ambiente. Uma visão preservacionista, portanto, considera apenas a conservação de áreas naturais para o uso do ser humano no presente e no futuro. Este ideal conservacionista baseia-se unicamente na visão da natureza enquanto fonte de recursos que, por sua vez, serão necessários futuramente à sobrevivência da espécie. Nota-se, mais uma vez, que não há uma preocupação fundamental com a natureza em si, mas somente com a espécie humana, que ocupa posição de destaque.

\section{Ambientalismo versus Antropocentrismo: o discurso ambientalista e as questões socioambientais}

A ideia que pretendo defender neste discurso diz respeito à necessidade de uma mudança de paradigmas que perpassa a questão dos valores atribuídos à natureza, compreendida a partir disto como alvo de nossas considerações morais. O discurso atual da sustentabilidade ambiental, assim como a justiça ambiental e social tem de, necessariamente considerar o valor atribuído ao meio ambiente como questão primordial, uma vez que a perpetuação dos valores antropocêntricos secularizados na sociedade nos conduziria à construção de princípios errôneos. 


\section{Ambientalismo e sustentabilidade: um olhar sobre o discurso ambiental}

O desenvolvimento da perspectiva ambientalista na atualidade deverá contribuir para esta mudança de foco, tendo em vista a mudança nos valores outrora propostos. Uma perspectiva ambientalista mais abrangente, isto é, que considera a natureza como alvo da moralidade humana, deverá lançar um novo olhar sobre a sociedade humana, propondo mudanças radicais em seu modus vivendis. Os movimentos ambientalistas que insurgem na história da humanidade apresentam ampla diversidade de enfoques e princípios éticos, contribuindo para o alargamento da moralidade humana.

O ambientalismo como movimento que percebe o meio ambiente em sua esfera política, econômica e social mostra-se como uma proposta de extrema importância para a transformação social e para a introdução de novas perspectivas de valor e conscientização das populações sobre a questão ambiental. Neste sentido, a abordagem do cientista político Enrique Leff nos auxilia a uma maior compreensão acerca do ambientalismo

“O ambientalismo abre portanto um processo de ressignificação do mundo atual. Além das deficiências do sistema produtivo para satisfazer as demandas dos consumidores, propõe uma crítica radical das necessidades. A perspectiva ambiental do desenvolvimento oferece um enfoque global e integrador sobre a realidade social; (...) $\mathrm{O}$ ambientalismo é um movimento pela diversificação das condições de existência e dos projetos de vida dos povos, que se projeta da heterogênese para uma diversidade de tipos de desenvolvimento. É uma utopia que mobiliza a ação para a construção de uma nova racionalidade produtiva e um projeto alternativo de civilização". (LEFF, 2008, pp. 101-102).

Dentro desta perspectiva, Leff chama atenção para uma mudança nos modos de produção e consumo da sociedade atual, sendo um dos aspectos centrais do movimento ambiental o questionamento das práticas que levaram à escassez de recursos e ao aumento da situação de pobreza em muitas regiões do planeta. É notável no fragmento acima, a proposta de uma ressignificação desta sociedade, capaz de produzir uma 'nova racionalidade produtiva', o que implica diretamente na mudança nos paradigmas político-econômicos que permeiam a questão ambiental. O movimento ambientalista que defende a sustentabilidade ambiental procura, assim, trazer à tona não somente aspectos críticos de desastres ambientais, mas também o debate entre o consumo desenfreado de populações ricas e o empobrecimento e a degradação das condições de vida de populações marginalizadas e, portanto, vulneráveis aos efeitos da fome, de doenças, da ausência de recursos materiais para a produção e sujeitas às catástrofes naturais.

A preocupação atual dos movimentos ambientalistas para com as populações em estado de vulnerabilidade socioambiental mostra-se como algo inovador para o discurso ambiental, uma vez que a visão que se adotava outrora, além de excluir questões sociais da arena ambiental, também 
NORUS - v3, n.4, jul - dez 2015.

considerava que ricos e pobres estavam igualmente sujeitos aos malefícios da crise ambiental e que todos sofreriam do mesmo modo os efeitos da escassez de recursos numa perspectiva global da crise. Esta concepção é combatida na atualidade, pois, apesar de válida no que tange aos efeitos globais de uma crise que afeta o ar, o consumo de água, entre outros, os efeitos de problemas como o aquecimento global e a degradação de terras pela produção agrícola, já são sentidos prioritariamente por populações vulneráveis que não possuem meios para alterar suas condições de vida. É um dos pontos comuns referentes à justiça ambiental e social a noção de que as populações pobres, por viverem em ambientes empobrecidos, expõem-se a doenças e outros males provenientes de um modelo excludente de desenvolvimento econômico (DOBSON, 1998).

Para fins ilustrativos desta questão, pode-se mencionar neste espaço o caso de uma grave tragédia socioambiental ocorrida na cidade de Niterói, RJ, no ano de 2010. O Morro do Bumba, em Niterói, abrigava uma comunidade de baixa renda quando da época em que ocorreu um grave deslizamento de terra levando à morte de mais de duzentas pessoas que ali viviam. O local, que era impróprio para a habitação, havia sido um depósito de lixo durante quinze anos até a década de 1980, quando foi desativado. Os detritos de lixo eram depositados no local sem qualquer tratamento, o que tornava a área perigosa também quanto ao contato com a toxicidade do lixo. No entanto, a partir dos anos 2000 a população carente que se instalou na região não recebeu alternativas de moradia, permanecendo no local. A prefeitura da cidade realizou obras de urbanização na região, ainda que se tratasse de uma área ilegal e imprópria. Informações mostram que anos antes do deslizamento foram feitas vistorias por membros da comunidade acadêmica vinculados à prefeitura local que consideraram a área inapropriada para habitação, com riscos não apenas de deslizamentos, mas também de explosões devido à presença de gases e contágio de doenças. Contudo, sem que medidas governamentais fossem tomadas para solucionar o problema desta população, o risco foi assumido até a data da catástrofe.

O caso citado mostra-se como um exemplo atordoante de uma história marcada pela degradação ambiental e pela ausência de planejamento urbano e social que culminaram na morte de centenas de pessoas. Para além da tragédia dos deslizamentos, nota-se que a tragédia ali referia-se ao próprio modo de vida daquela população em condições degradantes. Relatos mostram que o lixo depositado ainda produzia odores e líquidos que corriam próximos às casas, junto aos reservatórios de água. Diante destas condições de vida, infere-se que a tragédia já ocorria desde a sua instalação, demonstrando a ineficiência de um sistema que permite e, de certo modo, incentiva à urbanização de áreas de risco. Este mesmo sistema que permite que parte de sua população viva em condições 


\section{Ambientalismo e sustentabilidade: um olhar sobre o discurso ambiental}

como estas, promove programas de desenvolvimento ligados ao meio ambiente e à sustentabilidade, não considerando aquele ambiente como parte de sua estrutura ecológica.

Muitos casos como estes ainda ocorrem em diversas regiões pobres do planeta, indicando uma grave falha nos órgãos governamentais, nas políticas de urbanização do espaço social e no modo como as sociedades modernas se estruturam. Nota-se, com isto, que as deficiências do modelo de desenvolvimento humano pautadas na ideologia do crescimento econômico levam à exclusão de grande parte da sociedade que é submetida aos custos da poluição, ao aumento da degradação ambiental em seu espaço, à pobreza extrema e à marginalidade.

A indicação de problemas graves que afetam populações pobres de países em todo o globo nos parece ainda mais alarmante sobre este olhar do que outros problemas ambientais sofridos por populações abastadas, uma vez que a população rica é separada geograficamente das mais pobres e assim também não se expõe aos mesmos prejuízos que os mais pobres. Um problema ambiental possui uma conotação de 'possibilidade' na ótica das populações ricas, enquanto os mais pobres já vivenciam situações de escassez, degradação e riscos que afetam a saúde e a vida. O caráter de urgência de tais questões leva a uma diferenciação da questão ambiental, apontando agora para a justiça social referente à distribuição de recursos às populações pobres de todo o mundo, exigindo também a redução do consumo e da produção industrial em níveis tolerados pelo meio ambiente.

Neste aspecto, é possível inserir uma questão dirigida à ideia mesma de desenvolvimento adotada pela sociedade ocidental: quem são aqueles que se beneficiam das propostas de desenvolvimento? Quais são os custos deste desenvolvimento para o restante do planeta? O que está inserido na noção de 'qualidade de vida' para as populações ricas e pobres do mundo inteiro? Cabe agora desmistificar a ideia associada ao desenvolvimento e ao crescimento econômicos tomando-os como modelos precários que oferecem apenas soluções paliativas para as demandas de justiça socioambiental das populações pobres.

O questionamento acima nos remete ao ideal proposto pela visão ética que promove a sustentabilidade ambiental e a justiça social atrelada a esta. O movimento ambientalista, portanto, insere a questão da justiça social no cerne de seus debates, compreendendo que a melhor distribuição de recursos e a conscientização ambiental das populações ricas e pobres é condição para o desenvolvimento sustentável. As populações pobres, embora não se utilizem exaustivamente dos recursos, são privadas de benefícios e legadas à discriminação social. Uma parte do movimento ambientalista é voltada para luta pelos direitos básicos destas populações vulneráveis, uma vez que, conforme fora observado, estas populações sofrem os efeitos diretos da poluição decorrente do 
NORUS - v3, n.4, jul - dez 2015.

modelo excludente de desenvolvimento atual das sociedades. Neste aspecto, é possível refletir sobre a seguinte afirmação

"Questions of who pays and who benefits from contemporary policies of economic growth, industrial development, and environmental protection are at the heart of the environmental justice agenda". (EDWARDS apud DOBSON, 1998, p. 20)

Casos como o relatado acima acerca da tragédia dos deslizamentos em áreas de risco, a contaminação de populações que habitam locais impróprios com alta concentração de substâncias tóxicas, levaram o movimento ambientalista a assumir, assim, também a bandeira da justiça social. O movimento tem início nos Estados Unidos na década de 1970 quando uma população que fora levada a habitar um local no qual uma empresa química havia lançado detritos tóxicos num antigo canal aterrado começa a sofrer os danos na saúde, afetando inclusive futuras gerações que nasciam sob os efeitos dos produtos tóxicos que emergiam com a água das chuvas. Posteriormente, ativistas políticos engajaram-se nesta questão e promoveram, assim, a noção de justiça ambiental, introduzindo também a ideia de racismo ambiental (DOBSON, 1998). Esta concepção vai ao encontro da ideia de que a população que habita áreas de risco ocupa, de fato, as camadas mais pobres da sociedade e é também legada à exclusão social.

O movimento pró-justiça ambiental propõe, assim, que a ideia de justiça seja inserida no campo ambiental emergindo da luta pelos direitos humanos no que se refere ao direito a um ambiente saudável e a condições de vida dignas, expandindo até a inclusão de uma preocupação moral para com o futuro do planeta, do meio ambiente e da vida como um todo. O debate acerca da justiça ambiental caminha paralelamente à visão da sustentabilidade ambiental, uma vez que a melhoria das condições de vida das populações de um modo geral vincula-se à noção de desenvolvimento, isto é, ao modelo que se pretende construir de desenvolvimento, capaz de inserir agora questões socioambientais em seu escopo.

A relevância do debate sobre a sustentabilidade ambiental é notável na medida em que representa uma possibilidade de reduzir os impactos causados pelo modo de vida extravagante do ser humano, prioritariamente nos grandes centros urbanos. Apesar de observar certa ambiguidade na interpretação do termo 'desenvolvimento sustentável' como uma noção lançada para mesclar os interesses de uma economia capitalista à preservação ambiental que, por um lado ainda suprime a consideração moral para com a natureza e por outro lado, incentiva a economia a ajustar-se aos parâmetros de suporte do planeta, considera-se aqui que a sustentabilidade pode ser compreendida também como uma ideia de 'ambientalismo forte', isto é, que repensa as ações humanas procurando 


\section{Ambientalismo e sustentabilidade: um olhar sobre o discurso ambiental}

atribuir valor direto ao meio ambiente e assim tornar as instâncias e movimentos ambientais mais relevantes que os interesses econômicos de desenvolvimento.

Dentre os princípios propostos pelo movimento da justiça ambiental, ressalto apenas um deles destacado na obra do cientista político Andrew Dobson (1998) a ser apresentada. O movimento da justiça ambiental, tal como aspirado também pela proposta do desenvolvimento sustentável, requer que os recursos naturais renováveis sejam utilizados de modo 'ético, equilibrado e responsável' (DOBSON, 1998) tendo em vista a qualidade de vida das futuras gerações que não poderão viver num planeta em que detritos tóxicos são lançados a esmo levando os recursos naturais à sua extinção.

Em obra intitulada Justice and the Environment (Justiça e Meio Ambiente), Dobson trata dos conceitos de 'desenvolvimento sustentável' e 'sustentabilidade ambiental', atribuindo a estes uma concepção distinta. Dobson irá abordar a questão do meio ambiente a partir do conceito de 'sustentabilidade ambiental' e não mais de desenvolvimento, uma vez que a questão do 'desenvolvimento sustentável' está ainda atrelada a uma visão fortemente econômica da questão ambiental e deixaria de lado alguns aspectos importantes como a ideia de 'saúde ambiental'. Dobson introduz, assim, a discussão sobre os tipos de sustentabilidade, as diferentes vertentes da sustentabilidade, as diversas apropriações e definições do termo, encontrando assim, questões e respostas variadas para o mesmo conceito. A proposta de Dobson não é a de buscar uma definição precisa para o termo, mas antes discutir as diferentes perspectivas. Deste modo, Dobson define um método em que divide o conceito de sustentabilidade em grupos em que são apresentadas perguntas e respostas de acordo com cada característica deste tema. É feita também uma distinção entre a denominada 'sustentabilidade fraca' (Weak sustainability) e a 'sustentabilidade forte' (Strong sustainability), associando os diferentes conceitos às questões sobre a sustentabilidade aos dois grupos encontrados.

As questões que pretendem ser respondidas quanto ao conceito de sustentabilidade perpassam uma série de ideias sobre a relevância desta discussão. Afinal, questiona-se, ao que a ideia de sustentabilidade se aplica diretamente e quais são as ações viáveis para que se possa implementar este conceito no âmbito de nossas práticas sociais. Esta discussão fora apresentada por Luke e ressaltada por Dobson

As a social goal [...] sustainability is fraught with unresolved questions. Sustainable for how long: a generation, one century, a millennium, ten millennia? Sustainable at what level of human appropriation: individual households, local villages, major cities, entire nations, global economies? Sustainable for whom: all humans alive now, all humans that will ever live, all living beings living at this time, all living beings that will ever live? (DOBSON, 1998, p. 36). 
NORUS - v3, n.4, jul - dez 2015.

A questão central nesta discussão é demonstrar a necessidade de uma teoria acerca da ideia de sustentabilidade em estabelecer as perspectivas que irá assumir como ponto de partida para o problema ambiental. Quanto à questão sobre o que se estaria, assim, almejando sustentar e para quem, é possível encontrar aí a ideia da natureza somente enquanto fonte de recursos utilizados para todas as atividades humanas. Dobson faz uma distinção entre o que ele denomina 'capital natural' e 'capital natural crítico', observando que atualmente é mais comum que se fale em 'capital natural crítico' no que tange à noção de sustentabilidade, uma vez que se pode priorizar a preservação daquilo que não é mais abundante. Segundo Dobson, é somente a partir da visão acerca da escassez dos recursos naturais que foram desenvolvidas teorias de cunho ambiental. Atualmente, os recursos naturais não são mais abundantes e, por este motivo, são os recursos remanescentes que determinam o limite das ações humanas quanto à exploração destes (DALY apud DOBSON, 1998, p. 43). Devido a isto, é preferível que se adote o termo 'capital crítico' para o que se pretende abordar no discurso da sustentabilidade, definindo assim o foco da ideia de sustentabilidade, isto é, a sustentabilidade refere-se a tudo aquilo (recursos) que está em estado crítico e assim, precisa ser introduzido neste discurso. Dobson aponta para o estudo de Rapport que afirma que 'é a saúde do ecossistema aquilo que guia o desenvolvimento sustentável' (RAPPORT apud DOBSON, 1998, p. 44).

No que se refere à questão sobre a sustentabilidade 'para quem' ou 'de que', Dobson afirma que no mínimo "não é óbvio que a resposta deva ser sempre relacionada a algo instrumental ao bem-estar humano" (DOBSON, 1998, p. 45). Assim, provavelmente será também possível estabelecer que o meio ambiente seja preservado por seu valor intrínseco e não simplesmente instrumental.

Em sua distinção entre os tipos de teorias de sustentabilidade pode-se elencar três grupos principais nos quais estão dispostas algumas das concepções fundamentais adotadas no discurso da sustentabilidade. A primeira delas é a concepção denominada por Dobson de Substitutability. Nesta concepção de sustentabilidade, os recursos naturais são tomados a partir de seu valor instrumental e pode-se falar em substituir os elementos da natureza por objetos humanos, que tivessem uma função similar ao original, se isto fosse possível. Dobson cita o exemplo de uma possível criação de ‘árvores de plástico' que desempenhassem as mesmas funções das árvores reais e seriam, assim, facilmente substituídas sem prejuízos para o meio ambiente ou para a humanidade.

É possível que se encontre elementos que possam ser substituídos por outros sem prejuízos, não apenas substituídos por objetos criados pelo homem com as mesmas funções, mas, enquanto recursos renováveis, eles podem ser refeitos, a saber, as árvores de um modo geral podem ser 


\section{Ambientalismo e sustentabilidade: um olhar sobre o discurso ambiental}

replantadas sem prejuízos para as outras que foram utilizadas pelo homem; apesar disto, esta visão deve enfrentar o desafio de assumir que não são todos os recursos naturais que podem ser substituídos, isto é, os recursos não-renováveis devem ser preservados e mantidos para o futuro e, para que esta preservação seja possível, deve-se encontrar meios de substituir o uso destes recursos por outros que sejam renováveis.

No entanto, é chamada a atenção também para a visão de que há recursos que não são substituíveis por outros e também não são renováveis, tais como 'florestas tropicais' e 'processos ecológicos', que uma vez destruídos não seriam capazes de se reestabelecer do mesmo modo. Nestes casos, a alternativa proposta é que estes recursos devam ser mantidos em sua integridade, com vistas à preservação também do bem-estar humano nesta primeira concepção de sustentabilidade.

A segunda concepção abordada por Dobson aponta para a característica chamada Irreversibility dos recursos naturais, afirmando que agora não são as funções desempenhadas pelo elemento em seu ambiente que definem a sua importância para o sistema que habita, mas características como a unicidade dos elementos também devem ser levadas em consideração no que se refere ao valor atribuído à natureza. Dobson afirma sobre esta concepção de sustentabilidade que ela introduz um novo elemento ao modo em que comumente se interpretam as questões sobre os recursos naturais críticos e a noção de irreversibilidade. Ao passo que os recursos se tornam 'críticos' ou escassos podem prejudicar o modo de vida humano e não-humano. Para Dobson 'há muitas perdas irreversíveis (na natureza) que não são 'críticas' para os seres humanos de forma alguma' (DOBSON, 1998, p. 47).

Há de se ressaltar neste aspecto a posição de Dobson sobre a concepção da 'irreversibilidade' como uma visão que introduz a 'preocupação com aspectos da natureza em si mesmos' (DOBSON, 1998, p. 47). Assim, diferentemente da primeira concepção, esta não pensa a possibilidade de substituição dos recursos naturais, mas afirma que alguns recursos não-renováveis devem ser considerados em si mesmos, em suas características relevantes para o ecossistema natural e não para o uso humano, apesar de serem também úteis aos fins humanos. Para Dobson, pautandose na argumentação de economistas, alguns recursos que sejam insubstituíveis na natureza devem ser preservados em si mesmos, uma vez que os cálculos de troca e substituição não se aplicariam nestas situações, corroborando para a atribuição de um valor intrínseco a estes elementos críticos, a saber, espécies em extinção, Grand Canyon, Florestas Nacionais, entre outros que não podem ser refeitos igualmente pelo homem. 
NORUS - v3, n.4, jul - dez 2015.

A terceira concepção de sustentabilidade proposta por Dobson, tal como a anterior, propõe que a natureza e seus elementos sejam pensados a partir de seu valor intrínseco. Nesta concepção, por outro lado, o valor dos elementos não se deve ao uso instrumental destes, mas a sua relevância será medida a partir de sua história ou de características que os tornem significativos em si mesmos. É fato que todos se beneficiarão com a preservação das áreas naturais, incluindo as futuras gerações, no entanto, este não é o objetivo central neste tipo de concepção ambiental, mas esta perspectiva é também denominada de 'concepção do valor natural' ou green theory of value.

Nesta perspectiva é possível se tratar de obrigações morais para com a natureza, sendo uma concepção de 'sustentabilidade muito forte' em que não se propõe a substituição ou renovação dos elementos naturais, mas observa-se as características e os valores inerentes aos elementos. Segundo pensadores que defendem esta visão, os elementos devem ser mantidos em seus processos e componentes históricos, tomando os aspectos históricos dos elementos como tudo aquilo que não é reprodutível. Nesta concepção, as formações naturais como o Grand Canyon, ainda que sejam substituídos por outras formações geofísicas, jamais terão o mesmo valor do que o original.

Assim, ainda que sejam criados elementos similares cujas funções sejam as mesmas, tal como fora proposto na primeira concepção de sustentabilidade, suas características principais já teriam sido alteradas e o elemento então teria perdido o seu valor de originalidade composto pela história de sua formação. Nesta concepção, portanto, o valor é atribuído ao elemento independentemente da instrumentalização feita pelo homem, mas o processo histórico constitui-se como um valor em si que fomenta a ideia de preservação destes elementos ou áreas naturais. Neste sentido, é possível então delinear uma visão de sustentabilidade que promova o bem-estar humano para as presentes e futuras gerações, de seres humanos e não-humanos, bem como a preservação de ecossistemas e elementos cujo valor seja notável em si mesmo através de suas propriedades intrínsecas.

\section{Conclusão}

O presente trabalho procurou apresentar a concepção ambiental a partir de uma perspectiva de valores que consideram o meio ambiente como alvo de nossas considerações morais tendo em vista que ele integra relações sociais da humanidade aos aspectos ambientais. Fora analisado neste estudo o modo como os movimentos ambientalistas na atualidade inter-relacionam questões de justiça social e ambiental. Para tal, fora exposta uma crítica à noção de desenvolvimento econômico 


\section{Ambientalismo e sustentabilidade: um olhar sobre o discurso ambiental}

como aquele modelo de crescimento pautado na ideologia capitalista da produção e consumo. Do mesmo modo, a questão ambiental que decorre de uma reflexão sobre o atual modelo econômico, ainda é tomada superficialmente e embasada em concepções de valor antropocêntricos, excluindo do debate os impactos que este modelo de desenvolvimento imprimem na sociedade e nas populações pobres do mundo inteiro.

Fora introduzida, assim, a concepção da sustentabilidade ambiental, inicialmente a partir de um olhar crítico acerca do conceito de sustentabilidade e de seu uso corriqueiro, apontando para esta concepção como uma alternativa ao discurso único do desenvolvimento. Para que os problemas socioambientais sejam amenizados pela humanidade nas próximas décadas, é preciso, portanto, que se modifique o modo como as questões ambientais são tratadas, assim contribuindo para atingir a melhoria nas condições de vida de populações que vivem hoje em áreas pobres e degradadas.

Quanto às noções de sustentabilidade descritas pelas perspectivas de desenvolvimento econômico e ambiental, é importante que se distinga ao que se refere o discurso da sustentabilidade entre aqueles que promovem a ideia da substituição ou manejo dos recursos e aqueles que realmente fomentam ideais de justiça social e ambiental, assim como o bem-estar e o equilíbrio ambiental. A questão referente à produção da natureza discutida anteriormente deve ser pensada aqui a partir de um olhar ético no qual a natureza não seja mais tomada como fonte de recursos substituíveis e os riscos das atividades humanas sejam também minimizados.

Conforme fora observado nestas linhas, faz-se necessária a adoção de uma visão ética proposta por filósofos e ambientalistas que defendem a mudança nas práticas humanas e nos valores incutidos na sociedade, de modo a pensar a natureza não somente a partir de sua instrumentalização para os fins humanos, mas a partir de seu valor intrínseco. Propõe-se aqui que a partir desta modificação do olhar da humanidade para com o meio ambiente e para com a sociedade como um todo, reconhecendo-lhes valor em suas características fundamentais levaria à redução nos níveis de crescimento econômico associados aos maiores impactos ambientais globais.

É sugerida, por fim, pelos movimentos ambientalistas em suas críticas ao modelo econômico vigente a adoção de uma ética que atenda às necessidades básicas da humanidade, excluindo assim a ideia do consumo desmedido. Assim como colocado na afirmação de Leff, o ambientalismo é uma perspectiva crítica das necessidades humanas, trazendo à tona um novo significado aos conceitos de sociedade e natureza. As relações sociais agora, devem se ater a princípios éticos que fomentem práticas de uso e consumo conscientes de recursos, compreendidos não somente enquanto simples recursos, mas como elementos significativos da natureza. Da mesma forma, tal visão ética sugere 
NORUS - v3, n.4, jul - dez 2015.

que a relação com o outro em nossa sociedade considere suas necessidades fundamentais e que possamos refletir moralmente sobre nossas escolhas frente às necessidades fundamentais do outro.

\section{REFERÊNCIAS BIBLIOGRÁFICAS}

ALCÂNTARA, Lúcio. Desenvolvimento Sustentável. Cadernos de debates, coleção ideias, nº 2, Brasília, 2000.

BRUNTLAND, Gro et al. Our Commom Future: The World Comission on Environment and Development. Oxford: Oxford University Press, 1987.

CASTREE, Noel. e BRAUN, B. (orgs.). Social Nature: Theory, Practice, and Politics. Oxford: Blackwell Publishers, 2001.

CASTREE, Noel. Socializing Nature: Theory, Practice, and Politics. In: CASTREE e BRAUN. Social Nature: Theory, Practice, and Politics. Oxford: Blackwell Publishers, pp. 1-22, 2001.

DEAN, Warren. A ferro e fogo: a história e a devastação da Mata Atlântica brasileira. (Tradução: Cid Knipel Moreira). São Paulo: Companhia das Letras, 1996.

DEMERITT, David. Being Constructive about Nature. In: Castree e Braun. Social Nature: Theory, Practice, and Politics. Oxford: Blackwell Publishers, pp. 22-41, 2001.

DOBSON, Andrew. Justice and the Environment: Conceptions of Environmental Sustainability and Dimensions of Social Justice. New York: Oxford University Press, 1998.

(org.). Fairness and Futurity: Essays on Environmental Sustainability and Social Justice. Oxford: Oxford University Press, 2002.

FERRY, Luc. A Nova Ordem Ecológica: a árvore, o animal e o homem. (Tradução: Rejane Janowitzer). Rio de Janeiro: DIFEL, 2009.

GIDDENS, Anthony. Consequences of Modernity, Cambridge: Polity Press, 1990.

HARVEY, David. Justice, Nature and the Geography of Difference. Oxford: Blackwell Publishers, 1996.

JACOBS, Michael. Sustainable Development as a Contested Concept. In: DOBSON, Andrew. Fairness and Futurity: Essays on Environmental Sustainability and Social Justice. Oxford: Oxford University Press, pp. 21-45, 2002.

LEFF, Enrique. Saber Ambiental: sustentabilidade, racionalidade, complexidade, poder. (Tradução: Lúcia Mathilde Endlich Orth). Petrópolis: Vozes, 2008.

SINGER, Peter. Ética Prática. (Tradução: Jefferson Luiz Camargo). São Paulo: Martins Fontes, 1994.

. Um só mundo: A ética da Globalização. (Tradução: Adail Ubirajara Sobral). São Paulo: Martins Fontes, 2004. 
Ambientalismo e sustentabilidade: um olhar sobre o discurso ambiental

SWYNGEDOUW, Eric. Social Power and the Urbanization of Water: Flows of Power. Oxford University Press, 2004.

Modernity and Hibridity: Nature, Regeneracionismo, and the Production of the Spanish Waterscape, 1890-1930. In: Annals of the Association of American Geographers 89, n. 3, pp. 443-465, 1999. 